\title{
Outcomes and rate of return to play in elite athletes following arthroscopic surgery of the hip
}

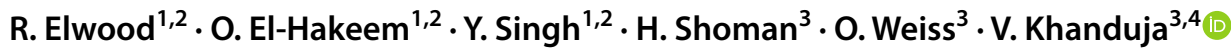

Received: 23 February 2021 / Accepted: 10 May 2021 / Published online: 19 June 2021

(c) The Author(s) 2021

\begin{abstract}
Background The tremendous physical demands of elite performance increase the risk of elite athletes sustaining various orthopaedic injuries. Hip pain is common in high-level athletes representing up to $6 \%$ of all athletic injuries. Expedient diagnosis and effective treatment are paramount for their future sporting careers and to prevent subsequent joint degeneration. Purpose This systematic review aimed to evaluate the outcome and the rate of return to play (RTP) following arthroscopic procedures in the hip (osteoplasty, chondroplasty, labral repair and/or debridement, capsulotomy, capsulorrhaphy or any soft tissue procedure) in elite athletes. Elite athletes were defined as those who represented their country in international contests or were competing professionally for the purpose of this study.

Methods A computer-based systematic search, following the PRISMA Guidelines, was performed on CENTRAL, PUBMED, EMBASE, SCOPUS, EBSCO, Google Scholar and Web of Science from inception until January 1, 2020, identifying studies that looked at return to sports post-hip arthroscopy in elite athletes. Weighted means were calculated for the RTP rate and duration and for patient-reported outcome measures (PROMs).

Results After eligibility screening, 22 articles were included with a total of 999 male and seven female patients, 1146 hips and a mean age of $28.4 \pm 3.2$ years. The mean follow-up period was $35.8 \pm 13.4$ months and $15.9 \pm 9.6 \%$ of athletes had undergone bilateral procedures. Overall, 93.9\% (95\% CI: 90.5, 96.6, $P<0.0001$ ) of patients demonstrated RTP after $6.8 \pm 2.1$ months post-surgery and all PROMs improved post-operatively. During follow-up, 9.6\% (95\% CI: 5.2, 15.2, $P=0.025)$ patients needed further intervention.

Conclusion A high percentage of elite athletes return to the same level of competition after hip arthroscopy, with a low rate of further interventions. Hip arthroscopy appears to be an efficacious treatment for hip and/or groin pain, caused by pathologies such as FAI or labral tears, in elite athletes in the shorter term. Long term outcomes need further evaluation.
\end{abstract}

Keywords Hip arthroscopy $\cdot$ Elite $\cdot$ Athletes $\cdot$ Professional sports $\cdot$ Outcomes $\cdot$ Return to play

This manuscript has not been published or presented elsewhere and is not under consideration by another journal

V. Khanduja

vk279@cam.ac.uk

1 School of Clinical Medicine, University of Cambridge, Cambridge, UK

2 Addenbrooke's - Cambridge University Hospital NHS Foundation Trust, Hills Road, Cambridge CB2 0QQ, UK

3 Young Adult Hip Service, Department of Trauma and Orthopaedics, Addenbrooke's - Cambridge University Hospitals NHS Foundation Trust, Box 37, Hills Road, CB2 0QQ Cambridge, UK

4 Mobius Health, Nuffield Hospital, 4 Trumpington Road, Cambridge CB2 8AF, UK

\section{Introduction}

The physical demands associated with elite levels of play place elite athletes at an increased risk of sustaining a variety of orthopaedic injuries [11, 24, 28, 44]. Pain around the hip is common in high-level athletes and can be due to a variety of conditions and pathologies representing up to $6 \%$ of all athletic injuries [4, 12, 32, 48].

Elite athletes, representing their country in international contests or competing professionally, often rely on high-impact activities for high-level performance, such as jumping, sprinting and cutting [7]. Forceful hip flexion, abduction and external rotation combined with repetitive loading have been shown to promote chondrolabral dysfunction, separation between the labrum and 
articular margin [42] which may lead to further damage to the hip, development of early-onset hip osteoarthritis $[1,2,6,19,20,54]$ and eventually the need for total hip arthroplasty. Two of the most common hip pathologies among elite athletes are labral tears occuring acutely and femoroacetabular impingement (FAI) which in itself may lead to labral pathology. The latter results from abnormal contact between the proximal femur and acetabulum secondary to a loss of sphericity at the femoral head-neck junction (cam) or acetabular overcoverage of the femoral head (pincer). Furthermore, studies have shown that high-intensity sports during adolescence may also lead to the development of a cam-type deformity [34, 39, 49].

Such hip pathologies are a potential cause of significant disability and may substantially affect the subsequent performance and career longevity of elite athletes. As such, it is important that players, team physicians, athletic trainers and coaches understand the potential career risks and benefits when operative management is indicated.

Expedient diagnosis and effective treatment are paramount for allowing athletes to continue their sports career and prevent subsequent joint degeneration. The understanding and diagnosis of femoroacetabular impingement (FAI) has increased over recent years, and a number of these athletes were likely misdiagnosed as having a "strain" when the aetiology of pain was truly FAI $[11,18]$.

Recent studies have demonstrated high return to play (RTP) rates within an athletic population [31,37]; however, no study has systematically looked at rates of RTP within an elite athletic population or reviewed the time to RTP, which is another important factor to consider for the elite athlete whose income may depend on their ability to compete. Several studies have shown the outcome of arthroscopic hip procedures to treat various hip pathologies among athletes in different sports professions. These prior studies demonstrated high rates of RTP in professional sports such as ice hockey, football, soccer, baseball, golf and basketball [14, 22, 26, $27,29,35,43]$. The performance outcomes and return to activity rates of elite athletes after hip arthroscopy are, however, currently unknown.

The purpose of this systematic review is to evaluate the outcome and the rate of return to play after arthroscopic procedures in the hip (osteoplasty, chondroplasty, labral repair and/or debridement, capsulotomy, capsulorrhaphy or any soft tissue procedure) amongst elite athletes. Our hypothesis is that there will be a higher level of return to play within the elite compared to the general athletic population, given the strong personal motivation, often financial, of these athletes and their access to quality resources and rehabilitation regimes.

\section{Methods}

\section{Search strategy}

A computer-based systematic search that followed the Preferred Reporting Items of Systematic Reviews and Meta-analysis (PRISMA) Guidelines [53] was performed using the following databases: CENTRAL (Cochrane Central Register of Controlled Trials), PUBMED, EMBASE, SCOPUS, EBSCO, Google Scholar and Web of Science Core Collection, for literature describing outcomes of hip arthroscopy among elite athletes.

All published studies from inception until January 1, 2020, were included in the systematic search. An a priori search algorithm using PubMed Medical Subject Headings (MeSH) terms was constructed. Duplicates were then removed electronically and manually. A detailed search strategy is described in the Appendix. The search function consisted of 3 search categories: studied population, procedure and confined to the hip joint. A total of seven combinations of keywords were combined together using Boolean terms AND/OR to create the following search strategy: "Athlete*" OR "Sport*" OR "Players" AND "Hip" AND "Arthroscopy" OR "Arthroscopic" OR "keyhole".

First, a blinded and independent process of selection based on title and abstract was made by two authors. Secondly, all studies were then assessed for eligibility using the pre-defined inclusion and exclusion criteria by titles and abstracts until full-text review. When discrepancies were found between the authors, a third author gave the final input until a consensus was reached. Reference lists of included articles were also screened for relevant articles.

The protocol of this systematic review was registered and published in the international prospective register of systematic reviews (PROSPERO) under the registration number: CRD42018115004 (https://www.crd.york.ac.uk/ prospero/).

\section{Eligibility criteria}

All published studies, from inception until January 1, 2020 , which reported the outcomes of hip arthroscopic surgery among elite athletes and met the following eligibility criteria, were included in the systematic search.

Studies were deemed eligible if they were written in English language and reported on human subjects with symptomatic hip pathology who have undergone primary hip arthroscopic (keyhole) surgery, including any of the following techniques: osteochondroplasty, chondroplasty, 
labral repair, reconstruction or labral debridement, capsulotomy or capsulorrhaphy and any soft tissue debridement. The subjects were required to be elite athletes of any sports, who have represented their country in international contests or were competing professionally. Minimum level IV evidence studies using Oxford Centre for EvidenceBased Medicine 2011 Levels of Evidence [38] were included. Exclusion of studies occurred if the subjects had a procedure using any implant, had any documented congenital or developmental paediatric hip disorders, such as Perthes disease, developmental dysplasia or slipped capital femoral epiphysis (SCFE) or had undergone any additional technique/procedure except the following: osteoplasty, chondroplasty labral repair and/or labral debridement, capsulotomy or capsulorrhaphy and any soft tissue debridement. Non-English language publications, animal or cadaveric studies, as well as reviews, hypothesis, technique, meta-analysis articles or oral presentations, were also excluded. Any excluded study, together with the reasons of exclusion, were noted.

\section{Quality assurance}

All eligible studies, as determined by the inclusion/exclusion criteria, were assessed and measured using the Risk Of Bias In Non-randomized Studies of Interventions (ROBINSI) scoring system and the Methodological Index for NonRandomized Studies (MINORS) scoring. Included studies were rated by two independent reviewers, who were blinded to author, affiliations and publishing journal. Any disagreements between reviewers were discussed in a consensus meeting and an independent arbitrator was employed when consensus could not be met. The results of this are summarized in Table 1.

\section{Data extraction and data synthesis}

The primary investigator (RE) extracted the relevant study data from the final pool of included articles and recorded this data on an Excel spreadsheet designed a priori.

Participant-specific demographics extracted from each study included the number of hips, gender distribution, mean age with range (years), mean BMI, length of follow-up, sports type, level of competition, surgical technique (labral repair or labral debridement) and rehabilitation intensity (duration and frequency). Outcome data, as presented in last follow-up, included clinical assessment (clinical scoring, pain scoring and level of satisfaction) and functional assessment, which included (rate to return to sports at the same competitive level, time to return to play,
Table 1 Quality assurance of included studies

\begin{tabular}{llll}
\hline Author & Year & $\begin{array}{l}\text { MINORS score } \\
\text { (risk of bias) }\end{array}$ & ROBINS-I score \\
\hline Jack et al. [16] & 2020 & High risk & Moderate \\
Jack et al. [17] & 2019 & High risk & Moderate \\
Sochacki et al. [51] & 2019 & High risk & Moderate \\
Sochacki et al. [50] & 2019 & High risk & Moderate \\
Lubbe et al. [23] & 2018 & High risk & Moderate \\
Barastegui et al. [5] & 2018 & High risk & Serious \\
Begly et al. [7] & 2018 & High risk & Moderate \\
Frangiamore et al. [13] & 2018 & High risk & Moderate \\
Locks et al. [22] & 2018 & High risk & Moderate \\
Nwachukwu et al. [36] & 2018 & High risk & Moderate \\
Schallmo et al. [46] & 2018 & Low risk & Low \\
Menge et al. [29] & 2017 & High risk & Moderate \\
Menge et al. [30] & 2016 & High risk & Moderate \\
Newman et al. [35] & 2016 & High risk & Moderate \\
Amenabar et al. [3] & 2013 & High risk & Moderate \\
Boykin et al. [9] & 2013 & High risk & Moderate \\
McDonald et al. [27] & 2013 & Low risk & Low \\
Hammoud et al. [15] & 2012 & High risk & Serious \\
Philippon et al. [43] & 2010 & High risk & Low \\
Philippon et al. [41] & 2009 & High risk & Low \\
Philippon et al. [40] & 2007 & High risk & Moderate \\
Saw et al. [45] & 2004 & High risk & Low \\
\hline
\end{tabular}

post-operative career lengths and retirement rates at the end of the follow-up).

\section{Statistical analysis}

The method of data extraction and computation followed the approach outlined by the Cochrane Handbook for Systematic Reviews of Interventions.

The aggregate data of clinical studies were analyzed with a random effect proportion meta-analysis (chi-squared test- $\chi^{2}$ ), weighted for individual study size, with MedCalc (MedCalc Statistical Software version 18.9.1 (MedCalc Software bvba, Ostend, Belgium; http://www.medcalc.org; 2018)). According to all included studies, the alpha level was set at 0.05 and all $\mathrm{p}$ values were two tailed.

Weighted means were calculated for age, follow-up period, incidence of bilateral procedures, patient-reported outcome measures, rehabilitation regimes, rates of further interventions and career prognostic data (rate \& time of return to play, career length and retirement rate) and were determined by study enrollment data. These outcomes were summarized in forest plots, which included studies that reported the necessary data for inclusion. 


\section{Results}

The search returned a total of 2082 articles through database searching and 906 duplicate results were removed. One article was identified through manual searches using cross referencing. After duplicates were removed, 954 articles were screened based of their titles and abstracts. The 96 full-text articles were screened for eligibility criteria, and 74 articles were excluded: one non-English language study, three-level $\mathrm{V}$ evidence articles, two papers with cohorts duplicated in one of our included articles, three review article, three abstracts, six papers did not report return to play outcomes and 56 papers were irrelevant. Overall, twenty-two studies looking at hip arthroscopic surgical outcomes among elite athletes met the eligibility criteria and were used in the final systematic review (Fig. 1).

\section{Patient demographics}

In total, 999 male and seven female patients were identified, with 1146 hips and an adjusted mean age of $28.4 \pm 3.2$ years. The mean follow-up period, reported in five of the papers, was $35.8 \pm 13.4$ months. BMI data was lacking in most of the papers. The proportion of athletes who had undergone bilateral hip arthroscopies was $15.9 \pm 9.6 \%$ (Table 2). The results are certainly skewed towards the male population, but unfortunately, this is what has been reported and available in the literature.

\section{Sports and level of competition}

Four papers solely considered footballers, three were on soccer players, four were on (ice) hockey players, two were on baseball players, two looked at basketball players, one paper was on golfers and one paper was on Australian Rules footballers. The five remaining papers had a mixed cohort of athletes. The details of the sporting distribution of each paper are included in Table 2.

Three papers included professional athletes at the level of second national league or lower, 17 papers included professional athletes in the highest national league, three papers included players who had represented their country at an international level and one paper included some Olympic-level athletes. However, there may be some overlap between professional leagues and representation at the

Fig. 1 PRISMA flowchart

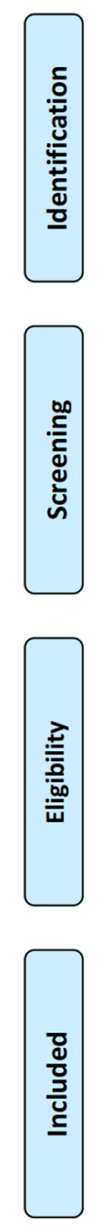

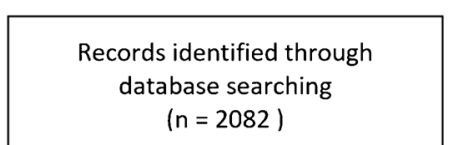

$(n=2082)$

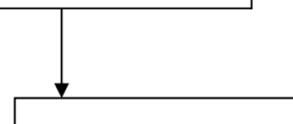

Records after duplicates removed

$(n=953+1)$
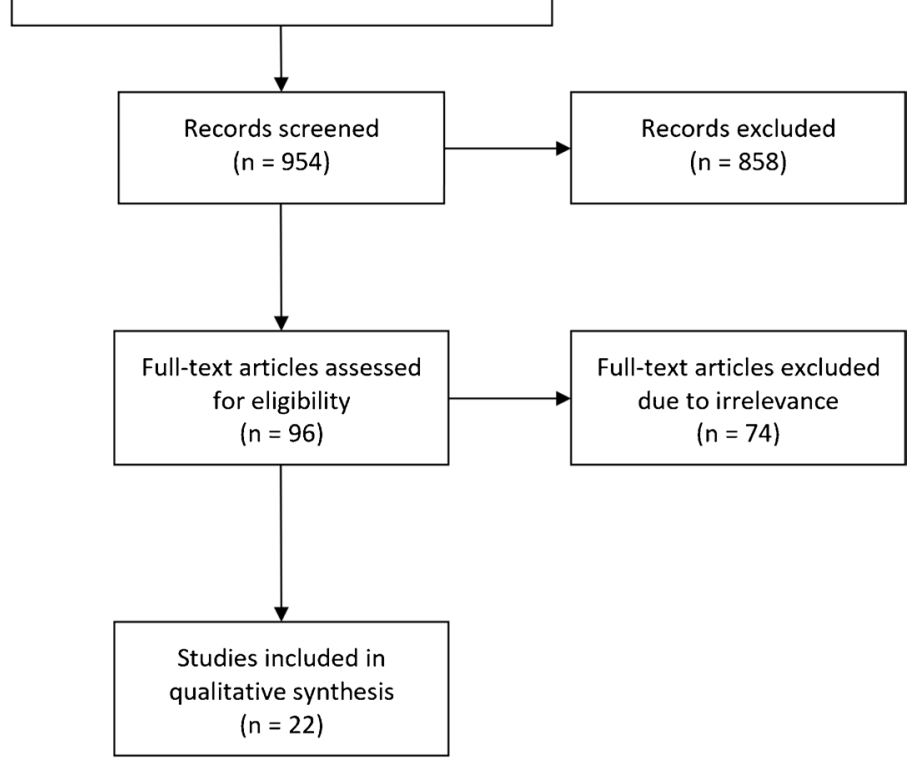

Additional records identified through other sources $(n=1)$

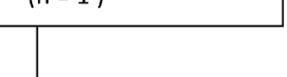

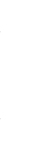


Table 2 Included studies examining outcomes of hip arthroscopy in elite athletes

\begin{tabular}{|c|c|c|c|c|c|c|c|}
\hline \multirow[b]{2}{*}{ Author } & \multirow[b]{2}{*}{ Year } & \multirow[b]{2}{*}{ Location } & \multicolumn{2}{|l|}{ Enrolment } & \multirow[b]{2}{*}{ Male (\%) } & \multirow[b]{2}{*}{ Mean age (y) } & \multirow[b]{2}{*}{ Sports type } \\
\hline & & & $\begin{array}{l}\text { Patients (\% of } \\
\text { total cohort) }\end{array}$ & Hips ( $\%$ of total cohort) & & & \\
\hline Jack et al. [16] & 2020 & USA & $23(2.3 \%)$ & $24(2.1 \%)$ & $100 \%$ & 27.5 & Basketball \\
\hline Jack et al. [17] & 2019 & USA & $50(5.0 \%)$ & $57(5.0 \%)$ & $100 \%$ & 30.4 & Baseball \\
\hline Sochacki et al. [51] & 2019 & USA & $71(7.1 \%)$ & $77(6.7 \%)$ & $100 \%$ & 29.4 & Ice hockey \\
\hline Sochacki et al. [50] & 2019 & USA & $55(5.5 \%)$ & $63(5.5 \%)$ & $100 \%$ & 27.5 & American football \\
\hline Lubbe et al. [23] & 2018 & USA & $64(6.4 \%)$ & $64(5.6 \%)$ & $100 \%$ & 30.3 & Ice hockey \\
\hline Barastegui et al. [5] & 2018 & Spain & $21(2.1 \%)$ & $21(1.8 \%)$ & $100 \%$ & 26.5 & Soccer \\
\hline Begly et al. [7] & 2018 & USA & $18(1.8 \%)$ & $24(2.1 \%)$ & $77.7 \%$ & 25.6 & Basketball \\
\hline Frangiamore et al. [13] & 2018 & USA & $44(4.4 \%)$ & $51(4.5 \%)$ & $100 \%$ & 26.6 & Baseball \\
\hline Locks et al. [22] & 2018 & USA & $24(2.4 \%)$ & $26(2.3 \%)$ & $100 \%$ & 25 & Soccer \\
\hline Nwachukwu et al. [36] & 2018 & USA & $40(4.0 \%)$ & $48(4.2 \%)$ & $100 \%$ & 25.6 & American football \\
\hline Schallmo et al. [46] & 2018 & USA & $180(17.9 \%)$ & $227(19.8 \%)$ & $100 \%$ & 28.9 & Mixed \\
\hline Menge et al. [29] & 2017 & USA & $51(5.1 \%)$ & $60(5.2 \%)$ & $100 \%$ & 27 & American football \\
\hline Menge et al. [30] & 2016 & USA & $60(6.0 \%)$ & $69(6.0 \%)$ & $100 \%$ & 27 & Ice hockey \\
\hline Newman et al. [35] & 2016 & USA & $20(2.0 \%)$ & $27(2.4 \%)$ & $100 \%$ & 38 & Golf \\
\hline Amenabar et al. [3] & 2013 & Australia & $26(2.6 \%)$ & $34(3.0 \%)$ & $100 \%$ & 21.8 & Australian Rules football \\
\hline Boykin, et al. [9] & 2013 & USA & $21(2.1 \%)$ & $23(2.0 \%)$ & $100 \%$ & 28 & Mixed \\
\hline McDonald et al. [27] & 2013 & USA & $120(12.0 \%)$ & $133(11.6 \%)$ & $100 \%$ & 29.1 & Mixed \\
\hline Hammoud et al. [15] & 2012 & USA & $38(3.8 \%)$ & $38(3.3 \%)$ & $100 \%$ & 31 & Mixed \\
\hline Philippon et al. [43] & 2010 & USA & $28(2.8 \%)$ & $28(2.4 \%)$ & $100 \%$ & 27 & Ice hockey \\
\hline Philippon et al. [41] & 2009 & USA & $1(0.1 \%)$ & $1(0.09 \%)$ & $100 \%$ & 25 & American football \\
\hline Philippon et al. [40] & 2007 & USA & $45(4.5 \%)$ & $45(3.9 \%)$ & $93.3 \%$ & 31 & Mixed \\
\hline Saw et al. [45] & 2004 & UK & $6(0.6 \%)$ & $6(0.5 \%)$ & $100 \%$ & - & Soccer \\
\hline
\end{tabular}

international or Olympic level, which may not have been reported. Four papers were not specific on the level of competition of the professional athletes that they included.

Table 3 Types of sports played by the study participants

\begin{tabular}{lll}
\hline Sport & $\begin{array}{l}\text { Number of partici- } \\
\text { pants (\%) }\end{array}$ & $\begin{array}{l}\text { Number } \\
\text { of studies } \\
(\%)\end{array}$ \\
\hline Ice hockey & $368(36.6 \%)$ & $9(40.9 \%)$ \\
American football & $248(24.7 \%)$ & $9(40.9 \%)$ \\
Baseball & $172(17.1 \%)$ & $7(31.8 \%)$ \\
Soccer & $72(7.2 \%)$ & $7(31.8 \%)$ \\
Basketball & $68(6.8 \%)$ & $5(22.7 \%)$ \\
Golf & $39(3.9 \%)$ & $3(13.6 \%)$ \\
Australian rules football & $26(2.6 \%)$ & $1(4.5 \%)$ \\
Tennis & $5(0.5 \%)$ & $2(9.1 \%)$ \\
Skiing & $2(0.2 \%)$ & $1(4.5 \%)$ \\
Ice skating & $2(0.2 \%)$ & $2(9.1 \%)$ \\
Dance & $2(0.2 \%)$ & $2(9.1 \%)$ \\
Martial arts & $1(0.1 \%)$ & $1(4.5 \%)$ \\
Jockey & $1(0.1 \%)$ & $1(4.5 \%)$ \\
\hline
\end{tabular}

Ice hockey, American football, baseball and soccer were the most reported sports, respectively (Table 3).

\section{Treatment (surgical technique, intra-operative findings/pathologies and post-op rehabilitation)}

A total of $68.7 \%$ (691 patients) had been diagnosed with FAI, and $41.3 \%$ (415 patients) diagnosed with labral pathology. Rim lesions and chondral lesions were also common with $4.8 \%$ (48) and $11.3 \%$ (114) patients respectively across the cohort. Ligamentum teres injuries were reported for $6.9 \%$ (69) patients. One paper reported 3.5\% (35) patients with micro-instability and another paper reported $2.7 \%$ (27) athletes with athletica pubalgia.

A variety of surgical techniques and procedures were performed across the papers. Osteochondroplasty was reported in 11 papers, with an average of $53.7 \%$ of patients across the eight papers that gave quantifiable data. Labral reconstruction or repair was reported in 15 papers with an average of $78.0 \%$ of patients undergoing the technique. Ten papers reported patients undergoing labral resection or debridement, performed on an average of $20.9 \%$ patients across these papers. Microfracture was reported in 14 papers, with an average of $18.2 \%$ patients across 13 papers. Acetabular 
rim trimming was reported in six papers, with an average of $75.2 \%$ patients undergoing the technique.

A consistently reported rehabilitation measure in the studies was weight-bearing protocols, which was reported in 14 studies. Twelve of these studies gave quantifiable data, with an average time of limited weight-bearing of $24.2 \pm 10.2$ days, including the patients that underwent longer rehabilitation after microfracture. The duration of limited weight-bearing protocols varies, but there is a consensus for eight weeks of limited weight-bearing following a microfracture. Six of these studies had a rehab regime where athletes were restricted to limited weight-bearing for two weeks or eight weeks if they had had microfracture.

\section{Patient-reported outcome measures (PROMs)}

Only $18.1 \%$ of the studies reported pre- and post-operative PROM scores. The mean weighted modified Harris Hip Score (mHHS) improved by $24.4 \%$ after hip arthroscopy (74.2 to 92.3). The mean weighted Nonarthritic Hip Score (NAHS) improved by $13.8 \%$ after hip arthroscopy ( 85.3 to 97.1) whilst the Hip Outcome Score sports (HOS-Sports) improved by $72.9 \%$ (47.2 to 81.6) and the Hip Outcome Score Activities of Daily Living (HOS ADL) improved by $24.8 \%$ ( 72.6 to 90.6 ). Table 3 shows the statistically significant improvements in all but one of the PROM scores in these studies (Table 4+Fig. 2).

\section{Return to play and follow-up}

Return to play was reported in all 22 studies; however, only thirteen papers defined return to play as competing at the same competitive level as prior to surgery. Overall, the average return to play was $93.9 \%$ (95\% CI: 90.5 , 96.6) $\left(\mathrm{I}^{2}=67.2 \%, P<0.0001\right)$. The average return to play at the same competitive level was $94.9 \%$ (95\% CI: 89.4 , 98.4) $\left(\mathrm{I}^{2}=75.1 \%, P<0.0002\right)$. The average time to return to play was reported in 14 papers with a mean time of $6.8 \pm 2.1$ months.

Nine papers reported that $22.8 \pm 19.0 \%$ of patients had retired at the end of the follow-up period, which was $26.8 \pm 19.3$ months (reported in seven papers). Seventeen papers also reported on the average career length of the athletes post-arthroscopy up until the end of the followup period, eight of these were reported as years played and the other nine were seasons played, averaging at $3.6 \pm 1.1$ years and $3.2 \pm 0.6$ seasons respectively (Fig. 3 and Table 5).

Nine papers reported on the requirement for further surgery, with an average of $9.6 \%$ (95\% CI: 5.2, 15.2) $\left(\mathrm{I}^{2}=54.3 \%\right.$, $P<0.03)$ of patients requiring future intervention.

\section{Quality of the studies}

All but four of the included studies were case series, with the exceptions being a case study, two cohort studies and a descriptive epidemiology study. The majority of these were level IV evidence. The papers ranged from serious to low risk of bias via ROBINS-I scoring, and MINORS scoring showed all but two of the included studies to be at high risk of bias. These are summarized in Table 1.

\section{Discussion}

This systematic review evaluated 22 clinical studies with a total of 1006 patients and 1146 hips to determine the average RTP in the elite athletic population, as well as RTP time, career lengths and PROM scores. All studies reported a percentage of their athletic population that returned to play; however, only 13 papers $(59.0 \%)$ reported a return to play at the same pre-operative competitive level. The overall RTP was 93.9\% (95\% CI: 90.5, 96.6) $\left(\mathrm{I}^{2}=67.2 \%\right.$, $P<0.0001)$ and $94.9 \%$ (95\% CI: $89.4,98.4)\left(\mathrm{I}^{2}=75.1 \%\right.$, $\mathrm{P}<0.0002)$ at the same competitive level, at an average time of $6.8 \pm 2.1$ months post-operative. This demonstrates a very high rate and speed of return to play in elite athletes. In contrast, O'Connor et al. [37] conducted a systematic review of return to sports in all levels of athletes after hip arthroscopy and found that the return to play rate was $84.6 \%$ (95\% CI: $80.4 \%-88.8 \% ; P=0.008)$ with a mean time to RTP of 7.4 months (95\% CI: 6.1-8.8). They found that the rate of return to sports within the recreational athletes in their cohort ranged from 66.7 to $84.0 \%$. In another paper, Minkara et al. [31] systematically reviewed the outcomes of arthroscopic surgery for FAI and found that $87.7 \%$ of patients returned to sports after surgery. A higher RTP in elite athletes compared to recreational or amateur athletes is unsurprising given their high motivation for recovery and access to high-quality resources. Most elite athletes are professionals; therefore, their livelihoods, as well as their sporting achievements, depend on a good and fast outcome. When compared to open surgical dislocation, arthroscopy results in

Table 4 Patient-reported outcome measures of the included studies

\begin{tabular}{lllc}
\hline & Pre-Op & Post-Op & \% improvement \\
\hline mHHS & 74.206 & 92.34717 & $24.4 \%$ \\
NAHS & 85.3 & 97.1 & $13.8 \%$ \\
HOS-SPORT & 47.2 & 81.62 & $72.9 \%$ \\
ADL HOS & 72.56 & 90.584 & $24.8 \%$ \\
SF-12 (physical) & 44 & 51 & $15.9 \%$ \\
SF-12 (mental) & 49 & 54 & $10.2 \%$ \\
VAS & 7.4 & 2.3 & $-68.9 \%$ \\
\hline
\end{tabular}


Fig. 2 Patient-reported outcome measures of the included studies

\section{Weighted improvement in patient-reported outcomes after hip arthroscopy}

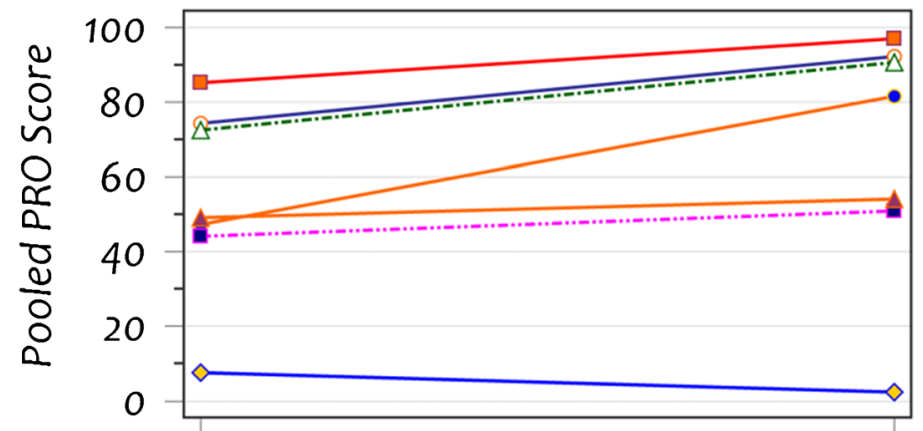

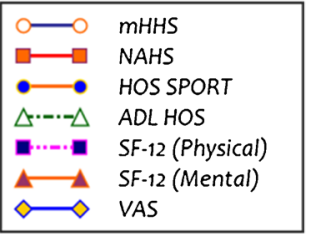

$\square$ NAHS

$\longrightarrow$ HOS SPORT

$\triangle \cdot-\triangle \quad A D L H O S$

$\rightarrow$ SF-12 (Mental)

$\Longleftrightarrow$ VAS a faster rate of RTP for professional athletes; the technique is minimally invasive creating a lower complication rate and a faster return to activity [8]. Career lengths after arthroscopy were reported in 17 papers to be $3.2 \pm 0.6$ seasons and $3.6 \pm 1.1$ years. This data would be more useful if reported uniformly as years post-operation due to the variability of season lengths between sports. Menge et al. [29] found that $92 \%$ of their cohort of NFL players had a minimum total career length of three years, which equals the average career length of players within the NFL.

There were a variety of rehabilitation protocols throughout the papers, ranging from no specific restricted weightbearing period [3] to four weeks of limited weight-bearing (8 weeks if microfracture) [40]. Despite many papers reporting longer rehabilitation times for microfracture, often eight weeks of limited weight-bearing, one paper found that elite athletes undergoing microfracture had no statistically significant difference in the rate of return to play [27]. Currently, rehabilitation protocols often depend on informal expert opinions rather than getting their basis from evidence, which at best is itself limited mostly to level IV evidence [37]. There needs to be more high-level evidence for rehabilitation protocols after hip arthroscopy, ideally randomized controlled trials looking at which protocols are most appropriate for athletes.

There was a lack of inclusion of standardized PROM scoring systems. Many of the studies did not include any PROMs, and for the few that did, there does not appear to be one scoring system that is favored against all of the others for a population of elite athletes. Many of the hip
Fig. 3 Individual study proportions and pooled estimate rates of return to sport
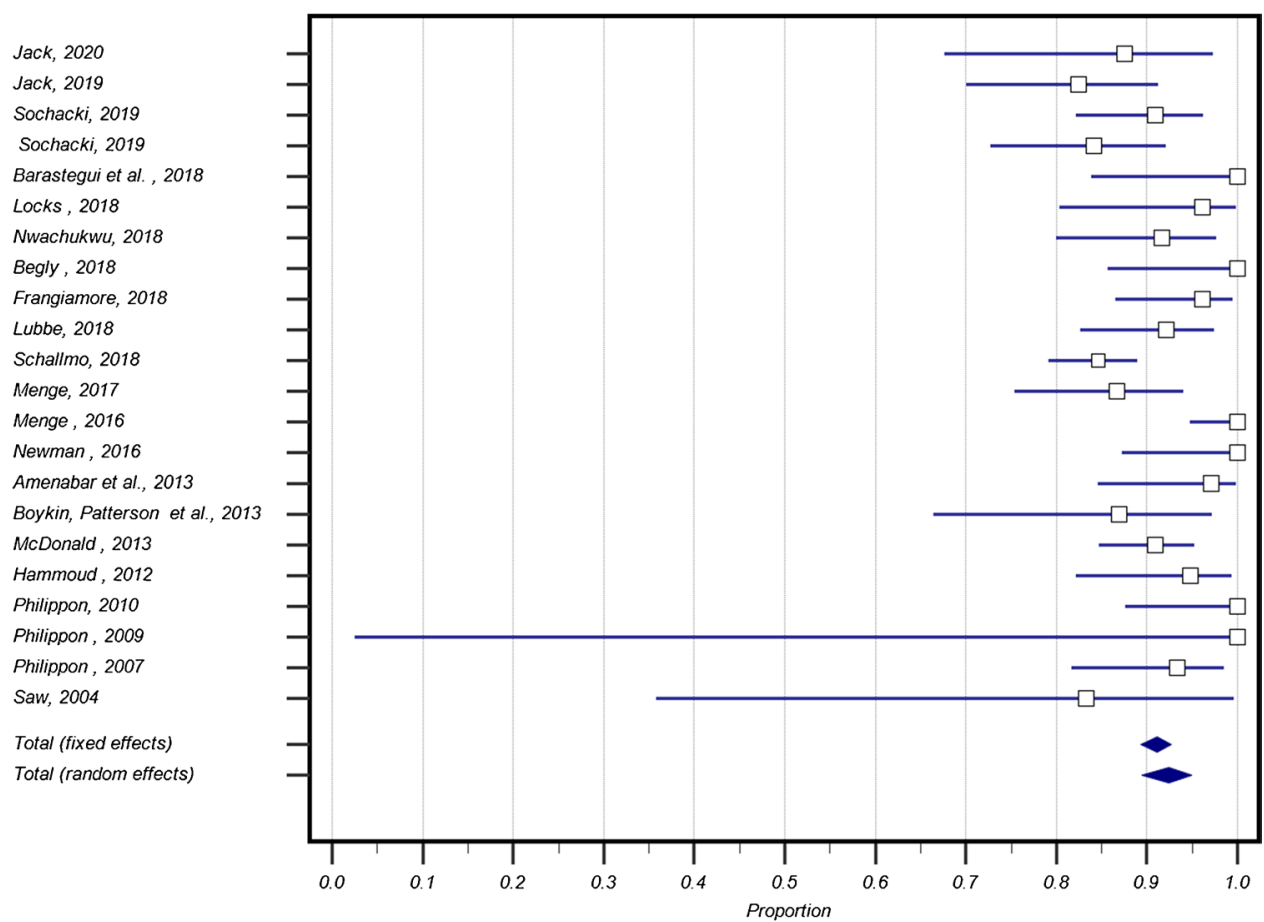
Table 5 Career lengths and return to play of athletes

\begin{tabular}{|c|c|c|c|c|c|c|c|c|}
\hline Author & Year & Patients (n) & $\begin{array}{l}\text { Mean } \\
\text { follow-up time } \\
\text { (months) }\end{array}$ & $\begin{array}{l}\text { RTP (\% of play- } \\
\text { ers) }\end{array}$ & $\begin{array}{l}\text { RTP time } \\
\text { (months) }\end{array}$ & $\begin{array}{l}\% \text { retired at } \\
\text { the end of last } \\
\text { follow-up }\end{array}$ & $\begin{array}{l}\% \text { patients that } \\
\text { required further } \\
\text { intervention }\end{array}$ & $\begin{array}{l}\text { Av. career length } \\
\text { after hip arthros- } \\
\text { copy at end of } \\
\text { follow-up }\end{array}$ \\
\hline Jack et al & 2020 & 23 & - & $86.9^{*}$ & 5.7 & - & - & 4.4 seasons \\
\hline Jack et al & 2019 & 50 & - & $82.5^{*}$ & 8.3 & 4.0 & - & 3.3 years \\
\hline Sochacki et al & 2019 & 71 & - & $90.9^{*}$ & 6.8 & 15.6 & - & 3.3 years \\
\hline Sochacki et al & 2019 & 55 & - & $84.1^{*}$ & 6.7 & 20.6 & 5.4 & 3.5 years \\
\hline $\begin{array}{l}\text { Barastegui et al. } \\
\text { [5] }\end{array}$ & 2018 & 21 & 45.4 & $100 *$ & 10.8 & 47.6 & - & 2.1 seasons \\
\hline Begly et al. [7] & 2018 & 18 & - & $100^{*}$ & 7.1 & - & - & 4 seasons \\
\hline $\begin{array}{l}\text { Frangiamore } \\
\text { et al. [13] }\end{array}$ & 2018 & 44 & - & $95.5^{*}$ & - & - & - & 3.6 seasons \\
\hline Locks et al. [22] & 2018 & 24 & - & $96^{*}$ & 9.2 & 66.7 & 4.2 & 4.3 years \\
\hline Lubbe et al & 2018 & 64 & - & $92.6^{*}$ & - & 7.4 & - & 3.1 seasons \\
\hline $\begin{array}{c}\text { Nwachukwu } \\
\text { et al. [36] }\end{array}$ & 2018 & 40 & - & $92.5^{*}$ & 6 & - & - & 3.1 seasons \\
\hline $\begin{array}{l}\text { Schallmo et al. } \\
\text { [46] }\end{array}$ & 2018 & 180 & - & $84.6^{\wedge *}$ & 6.9 & - & - & 2.7 years \\
\hline Menge et al. [29] & 2017 & 51 & - & 86.3 & - & - & 8.3 & 3.2 seasons \\
\hline Menge et al. [30] & 2016 & 60 & - & $100 *$ & - & 33.3 & - & 5.9 years \\
\hline $\begin{array}{l}\text { Newman et al. } \\
\text { [35] }\end{array}$ & 2016 & 20 & - & 100 & 4.7 & - & 10 & 5.72 years \\
\hline $\begin{array}{l}\text { Amenabar et al. } \\
\text { [3] }\end{array}$ & 2013 & 26 & 49.3 & 96 & - & 38 & 19.2 & 4.38 years \\
\hline Boykin, et al. [9] & 2013 & 21 & 41.4 & 85.7 & - & - & 19 & 3.6 seasons \\
\hline $\begin{array}{l}\text { McDonald et al. } \\
\text { [27] }\end{array}$ & 2013 & 120 & - & 90.8 & - & - & - & 2.9 seasons \\
\hline $\begin{array}{l}\text { Hammoud et al. } \\
{[15]}\end{array}$ & 2012 & 38 & - & 94.7 & 5.9 & - & - & - \\
\hline $\begin{array}{l}\text { Philippon et al. } \\
\text { [43] }\end{array}$ & 2010 & 28 & 24 & 100 & 3.8 & - & 7.1 & - \\
\hline $\begin{array}{l}\text { Philippon et al. } \\
\text { [41] }\end{array}$ & 2009 & 1 & - & 100 & 3.7 & - & - & - \\
\hline $\begin{array}{l}\text { Philippon et al. } \\
\text { [40] }\end{array}$ & 2007 & 45 & 19.2 & $93.3^{*}$ & - & 22.2 & 11.1 & - \\
\hline Saw et al. [45] & 2004 & 6 & - & 83.3 & 2.7 & - & 16.7 & - \\
\hline
\end{tabular}

*These papers specified their RTP time as the time until the same level of competition as pre-surgery.

${ }^{\wedge}$ This is the $\%$ of hips that returned to play since the paper did not report the \% RTP of athletes.

outcome scores were designed for activities of daily living and have limited application to sports activities, with the exception of HOS-Sports. We recommend that a consensus is needed on the most appropriate PROMs score for elite athletes, preferably one focused on sports-specific outcomes rather than activities of daily living, such as HOS-Sports, and reporting of these PROMs needs to be consistent across future studies.

A variety of sports were represented in the papers; however, the majority of sports included were the four major American sports (football, hockey, baseball and basketball), which may represent a bias in the data available. These sports have online databases, which allow for easy follow-up and retrospective analysis of return to sports and career length outcomes.

There needs to be a more standardized definition of "elite level"; it is often interchangeably with "competitive" or "professional". Some papers seem to include high school, collegiate and professional athletes in an "elite", "competitive" or "high-level" cohort [10, 47], whereas other papers defined elite athletes solely as professional athletes [27]. Even the definition of professional athletes is not definitive with Malviya et al. [25] defining anyone who played sports for a local club as a professional athlete. Swann et al. [52] found that there were eight different definitions of elite athletes within the literature, ranging from regional-level 
athletes with as little as two year experience in the sports to Olympic champions. They proposed a system for classification of elite status into four levels (based on answers to five variables): semi-elite (below the top standard of their sports), competitive elite (compete at the highest standard without success at that level), successful elite (compete at the highest standard with some success) and world-class elite (continued success over a prolonged period at the highest level). In order for future literature to allow for more specific definitions, we suggest more detail is needed in descriptions of athletic participation, especially the exact level of the league that the athletes compete in, their level of success and the length of time that they have competed at that level, which would allow for the application of Swann et al.'s (2015) classification system [52]. We defined "elite" as professional level or representation of their country because most of the literature seems to group athletes into high school, collegiate, professional or Olympic. Some papers included professional athletes in their cohorts; however, the data was impossible to extricate from the included high school and collegiate athletes. Whilst we recognize that some collegiate level athletes or even a few in high school may be playing at an elite level, there is a wide spectrum of level, which is difficult to regulate.

\section{Limitations}

Despite following the established systematic guidelines, we recognize that this study has several limitations. Firstly, the majority of papers included in this systematic review are level IV evidence (i.e. case series). There is a lack of higher quality literature in the field, particularly on elite-level athletes as demonstrated here. Randomized or blinded studies may be particularly difficult to elicit on the elite athletic population because of the high pressure for each individual athlete to make a rapid return to sports. Accordingly, the level of evidence that this systematic review represents is reduced; however, the aggregate data collated on the 1006 athletes included in this paper allows for more robust estimates of data than that of any single study.

Secondly, there is a distinct lack of data on female elite athletes. Many of the included studies are on athletes exclusively in professional male leagues so there is a lack of data on female athletes. Previous studies have suggested that females in general have poorer outcomes than males for arthroscopic treatment of FAI [33], suggesting that the outcomes from male elite athletes undergoing hip arthroscopy may not be generalizable to the female elite athletic population. There was also variation in the inclusion criteria for the included studies; some papers only included patients who had undergone surgery for FAI, whereas others included all patients that had undergone hip arthroscopy and some included patients who had undergone specific procedures.

Although many papers reported average career lengths post-surgery, inherently this data is inaccurate because, in many cases, we cannot be clear on whether athletes' careers ended due to reasons relating to their hip problems or from extrinsic factors. There is also a skew in the data because some athletes who are still competing at the end of the follow-up period may continue their athletic careers for many years past this point in time, likely creating an underestimate of career length.

Lastly, one of the major limitations faced when constructing this systematic review was the lack of a uniform definition of "elite", as discussed previously. Lots of data had to be excluded due to its grouping with other athlete levels such as high school and collegiate. There is no individual breakdown of the athletes within the literature, which makes it impossible to extract this data. A consistent and universally agreed definition of "elite" needs to be utilized in the future to increase the quality of the literature and any conclusions made from it.

\section{Conclusion}

This systematic review suggests that arthroscopic procedures in the hip (osteoplasty, chondroplasty, labral repair and/or debridement, capsulotomy, capsulorrhaphy or any soft tissue procedure) have good outcomes with $93.9 \%$ of athletes returning to play, often at the same level of competition as prior to the intervention. There is also a low rate of further interventions and good career lengths post-surgery, which suggest good future prognoses. Clearer reporting of elite athletes' demographics is now needed for better classification of athletes into elite and non-elite categories within the literature. There is currently a large variation in rehabilitation methods; higher levels of evidence are required here to establish best practice guidelines for surgeons and physiotherapists.

Author contributions R.E.: initial search and drafting of the manuscript, registration on Prospero

O.E.: initial search and filtering of the abstracts

Y.S.: initial search and filtering of the abstracts, manuscript preparation, registration on Prospero

O.W.: statistical help and assessing of papers

H.S.: statistics and assessing the quality of papers

V.K.: initial idea, formulation of the plan, manuscript preparation and overall responsibility of the study

Data availability Yes, no supplementary data. 


\section{Declarations}

Ethical approval Not required but the protocol for the study registered on Prospero. CRD42018115004. https://www.crd.york.ac.uk/prospero/.

Consent to participate Not applicable.

Consent to publish Yes.

Competing interests V.K. is on the Board of Directors for SICOT and is paid Educational Consultant for Arthrex, UK Limited and Smith and Nephew, UK Ltd.

Open Access This article is licensed under a Creative Commons Attribution 4.0 International License, which permits use, sharing, adaptation, distribution and reproduction in any medium or format, as long as you give appropriate credit to the original author(s) and the source, provide a link to the Creative Commons licence, and indicate if changes were made. The images or other third party material in this article are included in the article's Creative Commons licence, unless indicated otherwise in a credit line to the material. If material is not included in the article's Creative Commons licence and your intended use is not permitted by statutory regulation or exceeds the permitted use, you will need to obtain permission directly from the copyright holder. To view a copy of this licence, visit http://creativecommons.org/licenses/by/4.0/.

\section{References}

1. Agricola R, Heijboer MP, Bierma-Zeinstra SM, Verhaar JA, Weinans H, Waarsing JH (2013) Cam impingement causes osteoarthritis of the hip: a nationwide prospective cohort study (CHECK). Ann Rheum Dis 72:918-923

2. Alshameeri Z, Khanduja V (2014) The effect of femoro-acetabular impingement on the kinematics and kinetics of the hip joint. Int Orthop 38:1615-1620

3. Amenabar T, O'Donnell J (2013) Return to sport in Australian football league footballers after hip arthroscopy and midterm outcome. Arthroscopy 29:1188-1194

4. Anderson K, Strickland SM, Warren R (2001) Hip and groin injuries in athletes. Am J Sports Med 29:521-533

5. Barastegui D, Seijas R, Alvarez-Diaz P, Rivera E, AlentornGeli E, Steinbacher G et al (2018) Assessing long-term return to play after hip arthroscopy in football players evaluating risk factors for good prognosis. Knee Surg Sports Traumatol Arthrosc 26:963-968

6. Beck M, Kalhor M, Leunig M, Ganz R (2005) Hip morphology influences the pattern of damage to the acetabular cartilage: femoroacetabular impingement as a cause of early osteoarthritis of the hip. J Bone Joint Surg Br 87:1012-1018

7. Begly JP, Buckley PS, Utsunomiya H, Briggs KK, Philippon MJ (2018) Femoroacetabular impingement in professional basketball players: return to play, career length, and performance after hip arthroscopy. Am J Sports Med 46:3090-3096

8. Botser IB, Smith TW Jr, Nasser R, Domb BG (2011) Open surgical dislocation versus arthroscopy for femoroacetabular impingement: a comparison of clinical outcomes. Arthroscopy 27:270-278

9. Boykin RE, Patterson D, Briggs KK, Dee A, Philippon MJ (2013) Results of arthroscopic labral reconstruction of the hip in elite athletes. Am J Sports Med 41:2296-2301
10. Degen RM, Fields KG, Wentzel CS, Bartscherer B, Ranawat AS, Coleman SH et al (2016) Return-to-play rates following arthroscopic treatment of femoroacetabular impingement in competitive baseball players. Phys Sportsmed 44:385-390

11. Drakos MC, Domb B, Starkey C, Callahan L, Allen AA (2010) Injury in the national basketball association: a 17-year overview. Sports Health 2:284-290

12. Feeley BT, Kennelly S, Barnes RP, Muller MS, Kelly BT, Rodeo SA et al (2008) Epidemiology of National Football League training camp injuries from 1998 to 2007. Am J Sports Med 36:1597-1603

13. Frangiamore SJ, Mannava S, Briggs KK, McNamara S, Philippon MJ (2018) Career length and performance among professional baseball players returning to play after hip arthroscopy. Am J Sports Med 46:2588-2593

14. Frangiamore SJ, Mannava S, Briggs KK, McNamara S, Philippon MJJTAJoSM (2018) Career length and performance among professional baseball players returning to play after hip arthroscopy. 0363546518775420

15. Hammoud S, Bedi A, Magennis E, Meyers WC, Kelly BT (2012) High incidence of athletic pubalgia symptoms in professional athletes with symptomatic femoroacetabular impingement. Arthroscopy $28: 1388-1395$

16. Jack RA 2nd, Sochacki KR, Hirase T, Vickery J, McCulloch PC, Lintner DM et al (2020) Performance and return to sport after hip arthroscopy in the National Basketball Association. Arthroscopy 36:473-478

17. Jack RA, Sochacki KR, Hirase T, Vickery J, McCulloch PC, Lintner DM et al (2019) Performance and return to sport after hip arthroscopic surgery in Major League Baseball Players. Orthop J Sports Med 7:2325967119825835

18. Jackson TJ, Starkey C, McElhiney D, Domb BG (2013) Epidemiology of hip injuries in the National Basketball Association: a 24-year overview. Orthop J Sports Med 1:2325967113499130

19. Khanduja V, Villar RN (2007) The arthroscopic management of femoroacetabular impingement. Knee Surg Sports Traumatol Arthrosc 15:1035-1040

20. Kowalczuk M, Yeung M, Simunovic N, Ayeni OR (2015) Does femoroacetabular impingement contribute to the development of hip osteoarthritis? A systematic review. Sports Med Arthrosc Rev 23:174-179

21. Kujala UM, Kaprio J, Sarna S (1994) Osteoarthritis of weight bearing joints of lower limbs in former elite male athletes. BMJ 308:231-234

22. Locks R, Utsunomiya H, Briggs KK, McNamara S, Chahla J, Philippon MJ (2018) Return to play after hip arthroscopic surgery for femoroacetabular impingement in professional soccer players. Am J Sports Med 46:273-279

23. Lubbe RJ, Freshman RD, Singh G, Katchko KM, Schneider AD, Sharma S, et al. (2018) Performance outcomes and return-to-sport rate of National Hockey League athletes vary after common orthopedic surgical procedures. Clin J Sport Med. https://doi.org/10. 1097/JSM.0000000000000696

24. Mai HT, Alvarez AP, Freshman RD, Chun DS, Minhas SV, Patel AA et al (2016) The NFL Orthopaedic Surgery Outcomes Database (NO-SOD): the effect of common orthopaedic procedures on football careers. Am J Sports Med 44:2255-2262

25. Malviya A, Paliobeis CP, Villar RN (2013) Do professional athletes perform better than recreational athletes after arthroscopy for femoroacetabular impingement? Clin Orthop Relat Res 471:2477-2483

26. McDonald JE, Herzog MM, Philippon MJ (2014) Performance outcomes in professional hockey players following arthroscopic treatment of FAI and microfracture of the hip. Knee Surg Sports Traumatol Arthrosc 22:915-919 
27. McDonald JE, Herzog MM, Philippon MJ (2013) Return to play after hip arthroscopy with microfracture in elite athletes. Arthroscopy 29:330-335

28. McKay CD, Tufts RJ, Shaffer B, Meeuwisse WH (2014) The epidemiology of professional ice hockey injuries: a prospective report of six NHL seasons. Br J Sports Med 48:57-62

29. Menge TJ, Bhatia S, McNamara SC, Briggs KK, Philippon MJ (2017) Femoroacetabular impingement in professional football players: return to play and predictors of career length after hip arthroscopy. Am J Sports Med 45:1740-1744

30. Menge TJ, Briggs KK, Philippon MJ (2016) Predictors of length of career after hip arthroscopy for femoroacetabular impingement in professional hockey players. Am J Sports Med 44:2286-2291

31. Minkara AA, Westermann RW, Rosneck J, Lynch TS (2019) Systematic review and meta-analysis of outcomes after hip arthroscopy in femoroacetabular impingement. Am J Sports Med 47:488-500

32. Munegato D, Bigoni M, Gridavilla G, Olmi S, Cesana G, Zatti G (2015) Sports hernia and femoroacetabular impingement in athletes: a systematic review. World J Clin Cases 3:823-830

33. Mygind-Klavsen B, Lund B, Nielsen TG, Maagaard N, Kraemer O, Holmich P et al (2019) Danish Hip Arthroscopy Registry: predictors of outcome in patients with femoroacetabular impingement (FAI). Knee Surg Sports Traumatol Arthrosc 27:3110-3120

34. Nepple JJ, Vigdorchik JM, Clohisy JC (2015) What is the association between sports participation and the development of proximal femoral cam deformity? A systematic review and meta-analysis. Am J Sports Med 43:2833-2840

35. Newman JT, Saroki AJ, Briggs KK, Philippon MJ (2016) Return to elite level of play and performance in professional golfers after arthroscopic hip surgery. Orthop J Sports Med 4:2325967116643532

36. Nwachukwu BU, Bedi A, Premkumar A, Draovitch P, Kelly BT (2018) Characteristics and outcomes of arthroscopic femoroacetabular impingement surgery in the National Football League. Am J Sports Med 46:144-148

37. O'Connor M, Minkara AA, Westermann RW, Rosneck J, Lynch TS (2018) Return to play after hip arthroscopy: a systematic review and meta-analysis. Am J Sports Med 46:2780-2788

38. Obremskey WT, Pappas N, Attallah-Wasif E, Tornetta P 3rd, Bhandari M (2005) Level of evidence in orthopaedic journals. J Bone Joint Surg Am 87:2632-2638

39. Packer JD, Safran MR (2015) The etiology of primary femoroacetabular impingement: genetics or acquired deformity? J Hip Preserv Surg 2:249-257

40. Philippon M, Schenker M, Briggs K, Kuppersmith D (2007) Femoroacetabular impingement in 45 professional athletes: associated pathologies and return to sport following arthroscopic decompression. Knee Surg Sports Traumatol Arthrosc 15:908-914

41. Philippon MJ, Christensen JC, Wahoff MS (2009) Rehabilitation after arthroscopic repair of intra-articular disorders of the hip in a professional football athlete. J Sport Rehabil 18:118-134
42. Philippon MJ (2005) Schenker MLJOTiO. Athletic hip injuries and capsular laxity 15:261-266

43. Philippon MJ, Weiss DR, Kuppersmith DA, Briggs KK, Hay CJ (2010) Arthroscopic labral repair and treatment of femoroacetabular impingement in professional hockey players. Am J Sports Med 38:99-104

44. Posner M, Cameron KL, Wolf JM, Belmont PJ Jr, Owens BD (2011) Epidemiology of Major League Baseball injuries. Am J Sports Med 39:1676-1680

45. Saw T, Villar R (2004) Footballer's hip a report of six cases. J Bone Joint Surg Br 86:655-658

46. Schallmo MS, Fitzpatrick TH, Yancey HB, Marquez-Lara A, Luo TD, Stubbs AJ (2018) Return-to-play and performance outcomes of professional athletes in North America after hip arthroscopy from 1999 to 2016. Am J Sports Med 46:1959-1969

47. Shibata KR, Matsuda S, Safran MR (2017) Arthroscopic hip surgery in the elite athlete: comparison of female and male competitive athletes. Am J Sports Med 45:1730-1739

48. Shindle MK, Voos JE, Heyworth BE, Mintz DN, Moya LE, Buly RL et al (2007) Hip arthroscopy in the athletic patient: current techniques and spectrum of disease. J Bone Joint Surg Am 89(Suppl 3):29-43

49. Siebenrock KA, Behning A, Mamisch TC, Schwab JM (2013) Growth plate alteration precedes cam-type deformity in elite basketball players. Clin Orthop Relat Res 471:1084-1091

50. Sochacki KR, Jack RA 2nd, Hirase T, Vickery J, McCulloch PC, Lintner DM et al (2019) Performance and return to sport after femoroacetabular impingement surgery in National Football League players. Orthopedics 42:e423-e429

51. Sochacki KR, Jack RA, Hirase T, Vickery J, Harris JD (2019) Performance and return to sport after hip arthroscopy for femoracetabular impingement syndrome in National Hockey League players. Journal of Hip Preservation Surgery 6:234-240

52. Swann C, Moran A, Piggott D (2015) Defining elite athletes: issues in the study of expert performance in sport psychology. Psychol Sport Exerc 16:3-14

53. Swartz MK (2011) The PRISMA statement: a guideline for systematic reviews and meta-analyses. J Pediatr Health Care 25:1-2

54. Takeyama A, Naito M, Shiramizu K, Kiyama T (2009) Prevalence of femoroacetabular impingement in Asian patients with osteoarthritis of the hip. Int Orthop 33:1229-1232

55. Tveit M, Rosengren BE, Nilsson JA, Karlsson MK (2012) Former male elite athletes have a higher prevalence of osteoarthritis and arthroplasty in the hip and knee than expected. Am J Sports Med 40:527-533

56. Vingard E, Alfredsson L, Goldie I, Hogstedt C (1993) Sports and osteoarthrosis of the hip. An epidemiologic study. Am J Sports Med 21:195-200

Publisher's note Springer Nature remains neutral with regard to jurisdictional claims in published maps and institutional affiliations. 